Revistade
Economild
Contemporâned

\title{
POBREZA NO NORDESTE BRASILEIRO: UMA ANÁLISE MULTIDIMENSIONAL
}

\author{
Renata de Melo Caldas ${ }^{a}$ \\ Yony de Sá Barreto Sampaio ${ }^{b}$ \\ aPrograma de Pós-graduação em Economia da Universidade Federal de Pernambuco (PIMES/UFPE).

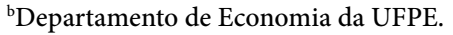

Artigo recebido em 08/07/2013 e aceito em 12/05/2015.

RESUMO: Este trabalho tem o objetivo de mapear o perfil da pobreza no Nordeste brasileiro no que concerne à carência de itens de consumo e habitação, e contrastá-la com a insuficiência de renda, que é o critério mais consolidado na literatura para se medir pobreza. Utilizando dados da Pesquisa Nacional por Amostra de Domicílios (PNAD) para o ano de 2009, a análise foi feita inicialmente para as macrorregiões brasileiras e, em seguida, para os estados da região Nordeste. Dentre os principais resultados, encontrou-se que a região Nordeste apresenta um dos maiores percentuais de domicílios sem acesso aos itens de habitação e consumo comparada às demais regiões do país, e é a pior em termos absolutos. Na dimensão de habitação, o item mais escasso em todas as macrorregiões é a água canalizada, enquanto na dimensão de consumo, geladeira é o que mais falta nos domicílios brasileiros. Constata-se ainda que, quando utilizado apenas o critério de renda, há muitos domicílios abaixo da linha de pobreza, mas que não apresentam carência nas demais dimensões analisadas.

CLASSIFICAÇÃO JEL: I32; O18; R11.

PALAVRAS-CHAVE: multidimensionalidade; Nordeste; pobreza.

Correspondência para: Renata de Melo Caldas.

E-mail: renatamcaldas@gmail.com 


\title{
POVERTY IN BRAZILIAN NORTHEAST: A MULTIDIMENSIONAL ANALYSIS
}

\begin{abstract}
This paper maps poverty profile of Brazilian Northeast regarding the lack of consumption and housing services, and contrasting them with income insufficiency, which is the most consolidated criterion to measured poverty in the international literature. We used data from the Nacional Survey for Housing Sample (PNAD, in Portuguese), in 2009. Among the main results, we found that the Northeast region has a huge percentage of households without access to housing services and consumer items comparatively to other regions and, moreover, this region is the worst in absolute terms. In the dimension of housing items, the scarcest item in all five macro regions is piped water, followed by sanitation (sewage) and electricity. Regarding consumption items, refrigerator is the most lacking item for Brazilian households. We also show that many families below the poverty line present no insufficiency in terms of housing and consumption dimensions.
\end{abstract}

KEYWORDS: multidimensionality; Northeast Brazil; poverty. 


\section{INTRODUÇÃO}

Frequentemente a pobreza é medida como escassez de renda, pois, por simplificação, a renda representa um meio para adquirir bens essenciais para sobrevivência. No entanto, a renda em si, como medida de pobreza, é bastante imprecisa tanto devido à dificuldade de informação de valores corretos, os quais são usualmente distorcidos (especialmente nas áreas rurais, onde a produção para autoconsumo ainda existe), como pelo fato de que ter renda não garante acesso aos bens essenciais. Mais recentemente, indicadores multidimensionais têm sido propostos, como fazem Alkire e Santos (2010) ou Alkire e Foster (2011), por exemplo. Porém, a ideia de usar um indicador esmaece bastante o retrato da pobreza, ainda que seja adotado um indicador que agregue várias dimensões deste problema. Uma análise multidimensional da pobreza deve destacar isoladamente dimensões como a privação de alimentos, de acesso a serviços de saúde e a uma rede pública de ensino de qualidade, de acesso à rede d'água, entre outras, que se fazem presentes ainda em uma grande parcela da população brasileira.

Segundo Arbache (2003), mais de $80 \%$ da população mundial vive com renda per capita inferior à brasileira. Este resultado sugere que a pobreza tratada unicamente como escassez de renda não é uma medida apropriada, uma vez que a privação de bens e serviços é uma característica importante, tornando-se essencial tratar dessas carências que ainda hoje atingem de forma intensa grande parcela da população brasileira. Uma visão multidimensional da pobreza não orienta apenas para um indicador de pobreza adequado, mas também mostra porque uma medida de pobreza baseada apenas na renda não serve para a mesma proposta (Anand e Sen, 1997).

Bourguignon e Chakravarty (2003) afirmam que uma pessoa é pobre se sua renda estiver abaixo da linha de pobreza. No entanto, segundo os próprios autores, a pobreza também é caracterizada pela insuficiência de bem-estar, determinada por variáveis monetárias e não monetárias, como habitação, alfabetização, expectativa de vida etc., tornando inapropriados indicadores que utilizem unicamente a renda monetária como medida de bem-estar. Anand e Sen (1997) consideram a pobreza como a pior forma de privação humana, que envolve não apenas o leque de necessidades materiais, mas também a falta de oportunidade de ter uma condição de vida tolerável.

De acordo com Mariano e Neder (2004), são diversas as consequências da pobreza, entre as quais se destacam a fome e miséria que recaem sobre as famílias que não conseguem auferir renda necessária para sobreviver. Segundo Marin e Ottonelli (2008), uma pessoa pode ser pobre por não ter acesso aos serviços básicos, como educação, saúde, energia elétrica, água encanada ou saneamento básico, e ainda por não ter capacitações básicas que são importantes para a liberdade de escolha entre diferentes tipos de vida. Ainda segundo os autores, uma política pública de combate à pobreza seria mais efetiva se atendesse às dimensões corretas. 
Tendo em vista os níveis alarmantes de incidência de pobreza na região Nordeste do Brasil, como foi alertado por Rocha (1995), é justificável que se busque a redução mais acelerada da pobreza nesta região, o que possivelmente resultará em uma redução da desigualdade regional da pobreza. Como nas áreas rurais a renda monetária representa apenas uma parcela da renda total, os cálculos para a pobreza utilizando-se apenas este critério enviesam os resultados para cima. Um critério de disponibilidade e acesso pode representar melhor a pobreza nessas regiões e permitir corrigir cálculos baseados apenas na renda.

Visto isto, o presente trabalho se propõe a analisar a pobreza no Nordeste brasileiro em termos multidimensionais, tanto com relação às demais macrorregiões quanto entre os estados dentro da própria região. Para isto, emprega dados extraídos da Pesquisa Nacional por Amostra de domicílios (PNAD), fornecida pelo Instituto Brasileiro de Geografia e Estatística (IBGE), para o ano de 2009. Compreender como determinadas variáveis estão presentes na caracterização da pobreza nordestina é essencial para direcionar políticas públicas mais eficientes, de modo que se consiga reduzir os efeitos adversos deste problema.

Além desta introdução, este trabalho está dividido em mais quatro seções. A seção 2 apresenta os dados e aspectos metodológicos utilizados na análise deste trabalho. As seções 3 e 4 mostram os principais resultados encontrados, inicialmente focando as características de habitação e consumo e, em seguida, mostrando como essas variáveis se relacionam com a renda. A última seção sumariza as principais conclusões.

\section{DADOS E METODOLOGIA}

Os dados utilizados nesse trabalho foram obtidos a partir dos microdados da PNAD, fornecidos pelo IBGE, para o ano de 2009. Nesse artigo, o foco será dado às famílias residentes nos estados do Nordeste, embora seja feita também uma comparação entre as macrorregiões brasileiras.

A unidade considerada neste estudo é o domicílio, ao invés do indivíduo, uma vez que, dessa forma, poderão ser captadas necessidades como consumo e habitação. A renda utilizada será o rendimento mensal domiciliar per capita em reais do ano de 2009.

A abordagem adotada no estudo consiste na análiseda condição de vida dos indivíduos, medida pelas variáveis habitação (acesso à água canalizada, rede de esgotos e existência de energia elétrica) e consumo (acesso a fogão, televisão e geladeira). Muitas outras variáveis poderiam ter sido incluídas no grupo de consumo, como telefone, microcomputador, máquina de lavar, rádio etc., porém, foram escolhidos os três itens citados acima pela sua relevância, especialmente no que se refere às questões de ali- 
mentação (como no caso de geladeira e fogão). Esses dois grupos de variáveis foram obtidos no arquivo de Domicílios da PNAD.

A caracterização de pobreza é feita a partir da carência desses serviços essenciais, seguindo-se a comparação com a insuficiência de renda, medida a partir de uma linha de pobreza. A partir da caracterização dos pobres, orientada pelo que já vem sendo estudado na literatura, serão estimadas sobreposições de tal forma que seja possível identificar as famílias cuja carência se dá em termos de renda e de outras variáveis (ver Figura 1).

\section{Figura 1 - Exemplo de sobreposições entre as variáveis que irão mensurar a pobreza em um aspecto multidimensional}

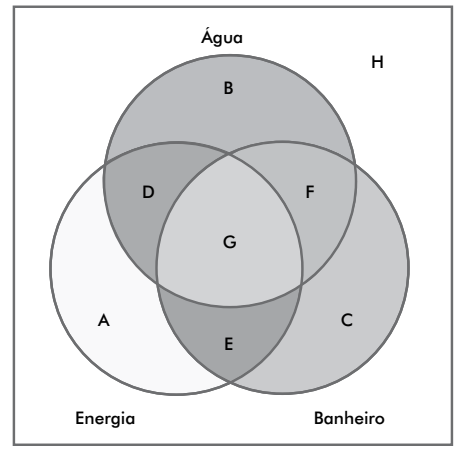

Fonte: Elaboração dos autores.

$\mathrm{Na}$ Figura 1, as áreas correspondentes às letras $\mathrm{A}, \mathrm{B}$ e C fazem referência à proporção de famílias que apresentam carência apenas em um dos três critérios: energia elétrica, água canalizada e esgoto sanitário, respectivamente. Ou seja, as famílias localizadas na região A são deficientes com relação à energia elétrica, mas possuem acesso à água canalizada e banheiro. Análise análoga será feita para as famílias localizadas nas regiões $\mathrm{B}$ e $\mathrm{C}$.

De modo semelhante, as regiões $\mathrm{D}, \mathrm{E}$ e $\mathrm{F}$ referem-se às famílias que não alcançaram dois, e apenas dois, dos três critérios estabelecidos, enquanto a área referente à letra $\mathrm{G}$ trata daqueles domicílios carentes dos três itens escolhidos para esta dimensão (habitação). A letra $\mathrm{H}$ representa os domicílios que possuem acesso aos três itens da dimensão, sendo apresentada em termos de mil unidades de domicílios, apenas para facilitar o entendimento das figuras. Da mesma forma, foram estimadas sobreposições para a dimensão de consumo, segmentada em acesso à geladeira, fogão e televisão.

A priori são apresentadas as sobreposições para o total das macrorregiões e para o Brasil e, em seguida, por estados do Nordeste. Isso será feito tanto para a dimensão de habitação quanto para consumo. Posteriormente, é feita uma análise a partir da inclusão da renda como uma das dimensões associadas à pobreza, a partir de uma linha de 
pobreza/indigência definida de acordo com o estabelecido pelo Instituto de Pesquisa Econômica Aplicada (IPEA) para o ano de $2009^{1}$. A inclusão desta variável é importante no sentido de verificar e contrastar a pobreza representada unicamente pela renda com a detectada a partir de carências específicas.

A linha de pobreza para a região Nordeste como um todo não foi disponibilizada. No entanto, o IPEA oferece as linhas referentes às áreas urbanas e rurais desta região. Para a área urbana, a linha de pobreza para o ano de 2009 foi de R $\$ 201,03$ mensais por pessoa, e a linha de indigência é calculada a partir da metade da linha de pobreza, ou seja, $\mathrm{R} \$ 100,51$. Já nas áreas rurais, a linha de pobreza foi de $\mathrm{R} \$ 179,29$ mensais por pessoa, e a linha de indigência foi de $\mathrm{R} \$ 89,65$ mensais por pessoa.

Considerando a renda e as dimensões consumo e habitação, os domicílios pobres foram classificados em cinco níveis:

- TIPO 1: Aqueles domicílios carentes nos três itens tanto na dimensão de consumo quanto de habitação, além de estarem abaixo da linha de pobreza/indigência. Este é o tipo mais severo da pobreza;

- TIPO 2: Aqueles domicílios carentes em pelo menos dois dos três itens tanto na dimensão de consumo quanto de habitação, além de estarem abaixo da linha de pobreza/indigência;

- TIPO 3: Aqueles domicílios carentes em pelo menos um dos três itens tanto na dimensão de consumo quanto de habitação, além de estarem abaixo da linha de pobreza/indigência.

- TIPO 4: Aqueles domicílios carentes em pelo menos um dos três itens tanto na dimensão de consumo quanto de habitação, mas que estão acima da linha de pobreza/indigência.

- TIPO 5: Aqueles domicílios que não são carentes em nenhum dos três itens nas dimensões de consumo e habitação, mas que estão abaixo da linha de pobreza/ indigência.

A importância desta análise decorre da inclusão dessas outras duas dimensões (consumo e habitação), uma vez que, repita-se, o uso exclusivo da renda como forma de mensurar pobreza não é o mais adequado. Desta forma, pode-se perceber a verdadeira carência tanto em termos de consumo quanto das demais necessidades dos indivíduos. Por exemplo, os indivíduos que se enquadrarem no TIPO 5, em especial, mostram que a renda não é um indicativo perfeito de pobreza, uma vez que as famílias enquadradas nesta categoria são consideradas pobres por não terem renda suficiente

1 Disponível em: <http://www.ipeadata.gov.br/doc/LinhasPobrezaRegionais.xls>. Acesso em: 04 abr. 2012. 
para atender aos requisitos mínimos, mas possuem acesso a todos os itens de habitação e consumo aqui considerados. Pelo contraste entre renda e outras dimensões pode-se considerar dois grandes tipos de erro: o de ter renda, mas apresentar carências nas outras dimensões, e o de não ter renda suficiente, mas não apresentar carências em termos de consumo e serviços de habitação. As consequências para a política social podem ser muito distintas para cada tipo de domicílio e para cada tipo de erro.

\section{ACESSO A ITENS DE HABITAÇÃO E CONSUMO PELAS FAMÍLIAS NORDESTINAS}

Os primeiros resultados referem-se à identificação das principais privações das famílias brasileiras em relação à habitação e consumo. A dimensão referente à habitação foi dividida em saneamento, energia elétrica e água canalizada; ou seja, será apresentada a participação das famílias que não tem um, dois ou nenhum dos três componentes de "habitação". Já o componente "consumo" foi segmentado em fogão (de uma ou mais bocas), geladeira e televisão (em preto e branco e/ou a cores). A análise para esse componente é análoga à da habitação.

O valor observado no extremo superior direito de cada figura representa o restante das famílias que não se enquadram em nenhuma das opções, ou seja, aquelas famílias que possuem os três itens. Além disso, este valor está em termos de mil unidades.

\subsection{HABITAÇÃO}

A Figura 2 mostra o número de famílias carentes nos itens de habitação para o Brasil e macrorregiões no ano de 2009. Percebe-se que o maior problema enfrentado em todas as regiões é o acesso à água canalizada. Isso pode ser visto pelo tamanho das circunferências de cada uma das variáveis, sendo este tamanho proporcional ao número de famílias sem acesso a tais itens. Enquanto isso, a cobertura de energia elétrica, dentre os três itens estudados nesta dimensão, é o que menos afeta as famílias em todas as regiões.

Dentre todas as áreas mostradas nas figuras, a mais importante é a interseção dos três componentes, representada pela área verde em cada um dos diagramas, pois representa aquelas famílias que não possuem acesso à água, à energia elétrica e nem ao esgoto sanitário. Analisando isoladamente as famílias em cada uma das regiões, verifica-se que pequenos percentuais destas não possuem nenhum dos três itens. Ou seja, $1,90 \%$ do total da população da região Norte não possui nenhum dos três itens de habitação, assim como $1,61 \%$ da população da região Nordeste, $0,06 \%$ da região 
Figura 2 - Total de famílias com carência de alguns itens de habitação, Brasil e Macrorregiões, 2009

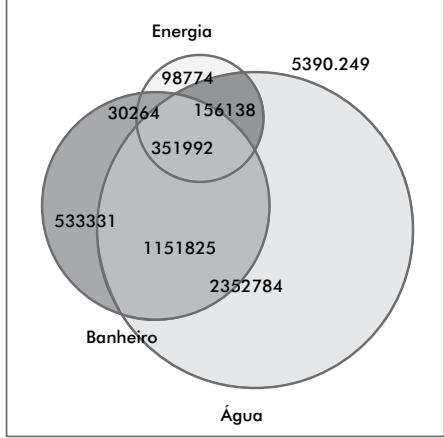

A. Brasil

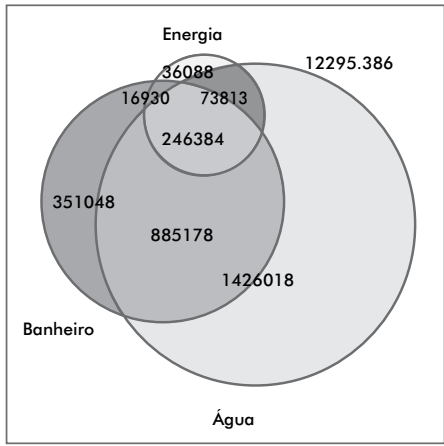

C. Nordeste

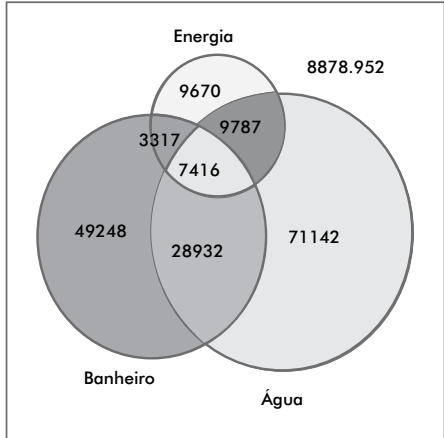

E. Sul

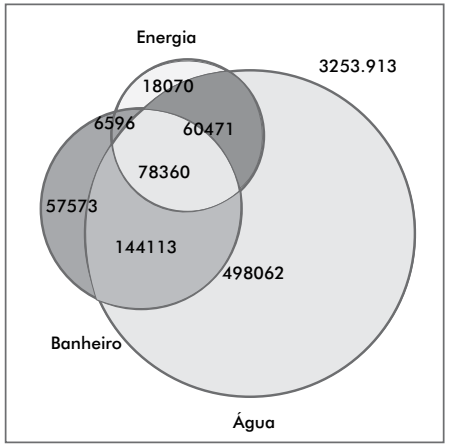

B. Norte

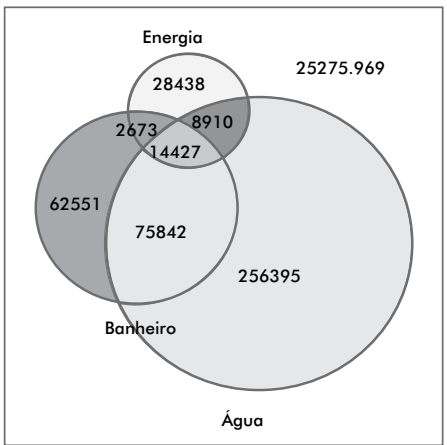

D. Sudeste

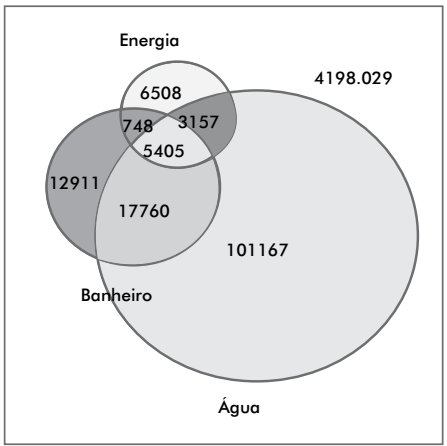

F. Centro-Oeste

Fonte: Elaboração própria com base em dados da PNAD 2009

Sudeste, $0,08 \%$ da região Sul e 0,12\% da região Centro-Oeste. Apesar disso, em valores absolutos, estes números tornam-se significativos, representando, no Brasil, 351.992 famílias, das quais 78.360 são famílias na região Norte, 246.384 são famílias no Nordeste, 14.427 no Sudeste, 7.416 no Sul e 5.405 no Centro-Oeste. 
Como esperado, as regiões Norte e Nordeste apresentaram resultados bem menos satisfatórios do que as demais regiões. Enquanto Sudeste, Sul e Centro-Oeste possuem menos de $0,5 \%$ de suas famílias sem acesso à energia elétrica, o Norte e Nordeste apresentam 3,97\% e 2,43\%, respectivamente, como pode ser visto com mais detalhes no Anexo 1. No que diz respeito à água canalizada, Norte e Nordeste possuem $18,97 \%$ e $17,16 \%$ de suas famílias sem acesso a esse serviço, respectivamente. Enquanto isso, as demais regiões apresentam percentuais bastante pequenos: $1,38 \%$ (Sudeste), 1,29\% (Sul) e 2,93\% (Centro-Oeste). Com relação ao acesso a banheiro, a situação também não é diferente, sendo que $6,96 \%$ das famílias na região Norte e9,78\% das famílias na região Nordeste não possuem acesso, enquanto apenas $0,60 \%$ das famílias no Sudeste, $0,98 \%$ no Sul e $0,85 \%$ no Centro-Oeste não o possuem.

A Figura 3 apresenta as mesmas características da figura anterior, no entanto, segmentada entre os estados da região Nordeste, que é o foco do nosso estudo. Percebe-se que os estados do Maranhão, Piauí e Bahia são os estados que possuem maior percentual de famílias carentes da região nas três dimensões, sendo 4,48\%, 5,97\% e 1,88\%, respectivamente. Pode-se dizer que $1,4 \%$ das famílias nordestinas não possuem nem energia elétrica, nem água canalizada e nem esgoto sanitário em suas residências, o equivalente a 210.542 domicílios.

Como pode ser visto no Anexo 1, os estados do Maranhão, Piauí e Alagoas são os que mais carecem de ajuda no que diz respeito à falta de água canalizada e de banheiro. Esses três estados possuem, respectivamente, 30,81\%, 27,16\% e 21,46\% das suas famílias sem acesso à água canalizada, enquanto $19,54 \%, 26,00 \%$ e $10,48 \%$ não possuem acesso a esgotamento sanitário.

\subsection{CONSUMO}

A próxima dimensão a ser estudada é referente ao consumo de bens duráveis pelas famílias no total das macrorregiões e nos estados do Nordeste. Foram escolhidos esses bens por serem de importância especialmente para a realização das necessidades básicas dos indivíduos.

A Figura 4 mostra como está o panorama do consumo no Brasil e nas cinco macrorregiões. Pelo que se pode observar, o item geladeira é o que mais falta nos domicílios brasileiros (6,59\%). Esta tendência segue para todas as macrorregiões, sendo 14,04\% para a região Norte, $15,47 \%$ para a região Nordeste, $2,24 \%$ na região Sudeste, $1,90 \%$ na região Sul e 3,77\% no Centro-Oeste. Mais uma vez, é notória a discrepância existente do consumo desse item entre as regiões Norte-Nordeste versus Centro-Sul do país. 
Figura 3a - Total de famílias com carência de alguns itens de habitação, Nordeste e Estados do Nordeste, 2009

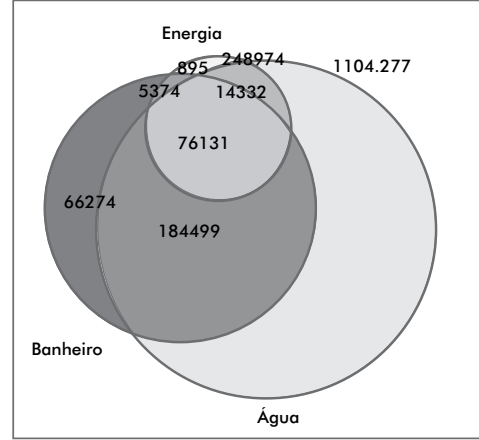

A. Maranhão

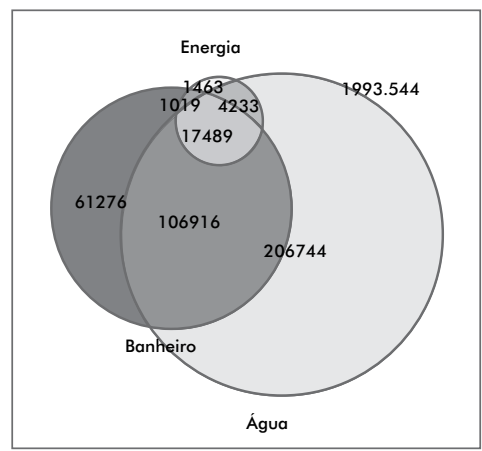

C. Ceará

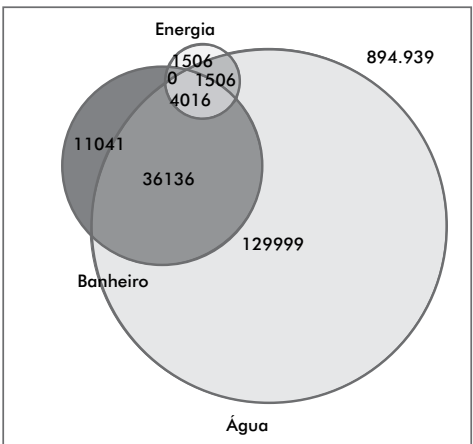

E. Paraíba

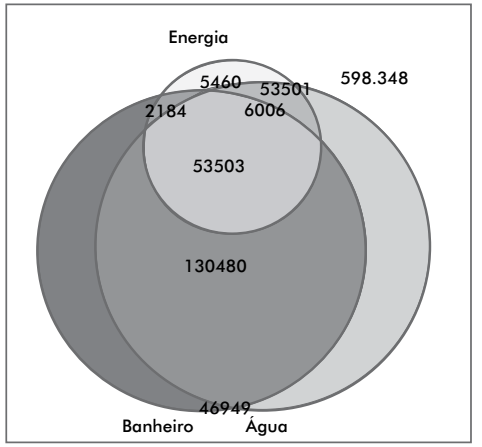

B. Piauí

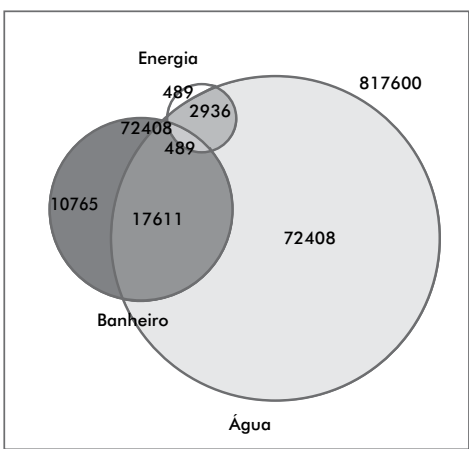

D. Rio Grande do Norte

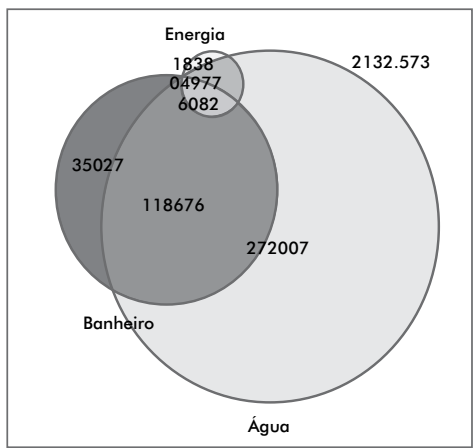

F. Pernambuco

Fonte: Elaboração própria com base em dados da PNAD 2009.

Interessante observar também que as regiões Sul e Centro-Oeste têm um percentual maior de domicílios sem televisão (3,09\% e 4,33\%, respectivamente) do que sem geladeira (1,90\% e 3,77\%), enquanto, nas demais regiões, 9,22\% (Norte), 7,47\% 


\section{Figura 3b - Total de famílias com carência de alguns itens de habitação, Nordeste e Estados do Nordeste, 2009}

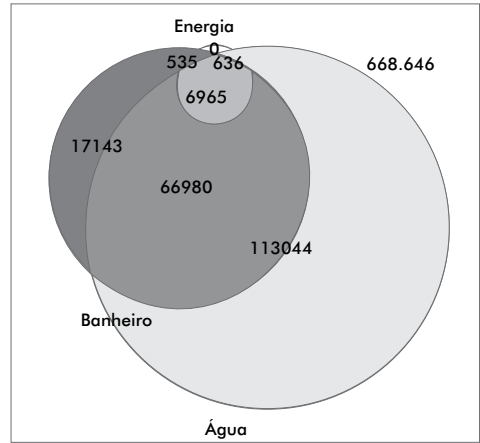

G. Alagoas

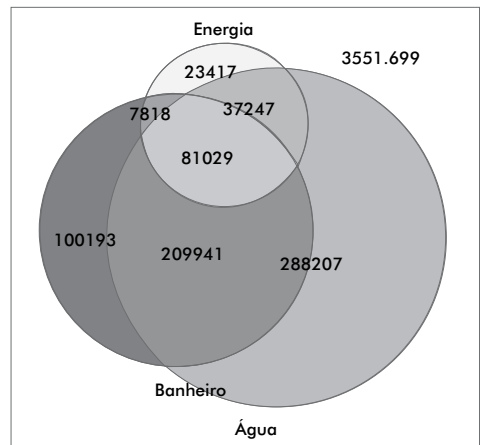

I. Bahia

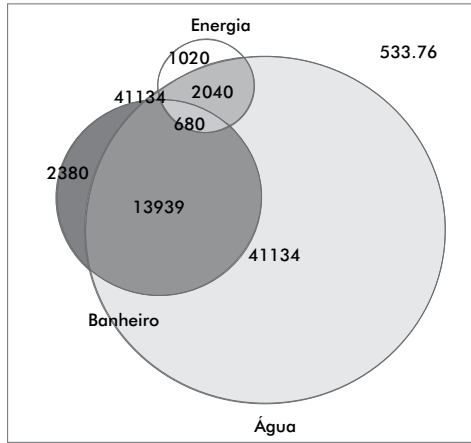

H. Sergipe

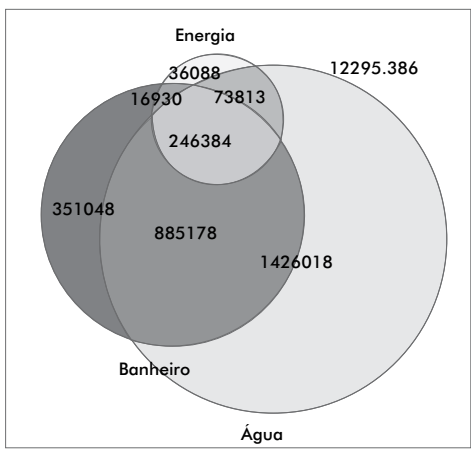

J. Nordeste

Fonte: Elaboração própria com base em dados da PNAD 2009

(Nordeste) e 2,10\% (Sudeste) dos domicílios não possuem televisão, e 14,04\%, 15,47\% e 2,24\% dos domicílios nessas regiões não possuem geladeira, respectivamente. Este resultado é, no mínimo, intrigante, uma vez que geladeira tem um papel mais essencial, em termos de saúde, por exemplo, do que uma televisão.

Das 233.025 famílias que não possuem nenhum dos três bens de consumo analisados (fogão, geladeira e televisão) no Brasil, quase $70 \%$ se encontram no Nordeste. Em termos absolutos, isso representa quase 7,79 vezes o número de famílias na região Sudeste que estão na mesma situação e 22,66 vezes o número de famílias na região Sul.

Assim como na dimensão de habitação, pequenos percentuais de domicílios em todas as regiões são carentes dos três itens de consumo (geladeira, televisão e fogão) conjuntamente. Ou seja, $0,88 \%$ do total da população da região Norte não possui nenhum dos três itens de consumo, assim como 1,03\% da população da região Nordeste, 
Figura 4 - Total de famílias com carência de alguns itens de Consumo, Brasil e Macrorregiões, 2009

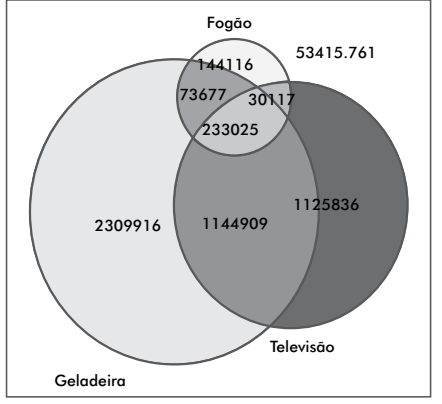

A. Brasil

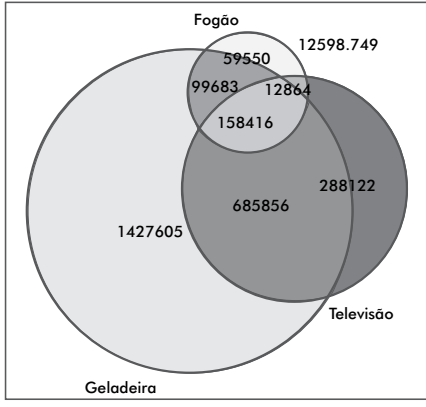

C. Nordeste

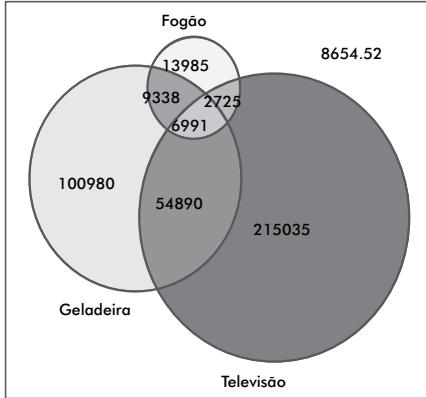

E. Sul
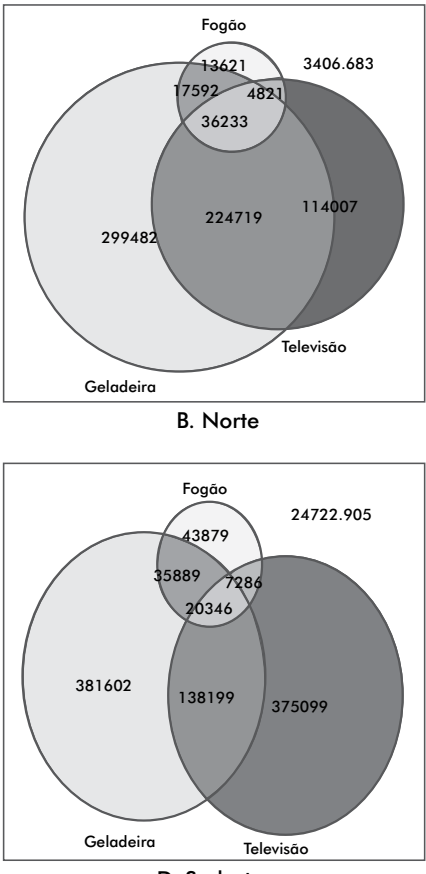

D. Sudeste

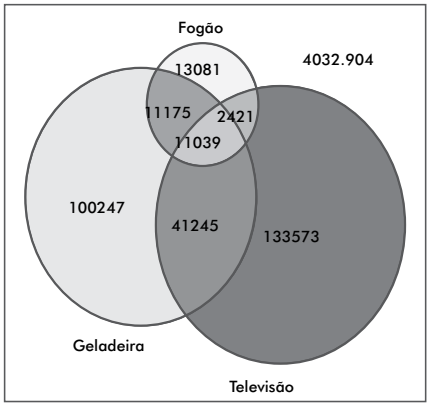

F. Centro-Oeste

Fonte: Elaboração própria com base em dados da PNAD 2009.

0,08\% da região Sudeste, $0,08 \%$ da região Sul e 0,25\% da região Centro-Oeste. Apesar disso, em valores absolutos, estes números tornam-se significativos especialmente para a região Nordeste, sendo 36.233 famílias na região Norte, 158.416 no Nordeste, 20.346 no Sudeste, 6.991 no Sul e 11.039 no Centro-Oeste.

Com relação aos estados do Nordeste, apresentado na Figura 5, Maranhão e Bahia são os estados com maior percentual de domicílios do Nordeste que não possuem nem 
Figura 5a - Total de famílias com carência de alguns itens de consumo, Nordeste e Estados do Nordeste, 2009

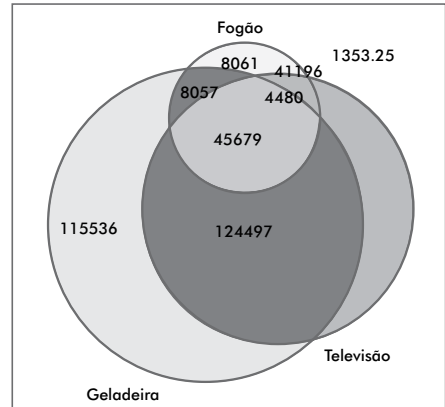

A. Maranhão

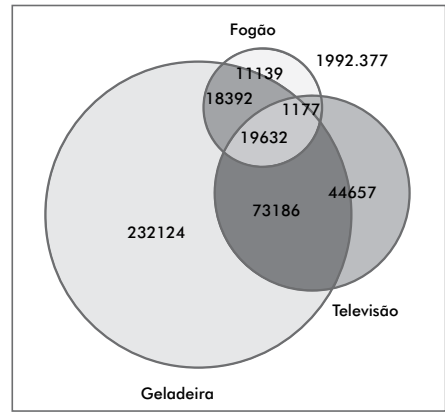

C. Ceará

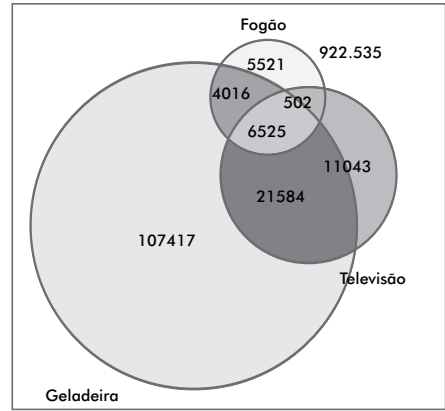

E. Paraíba

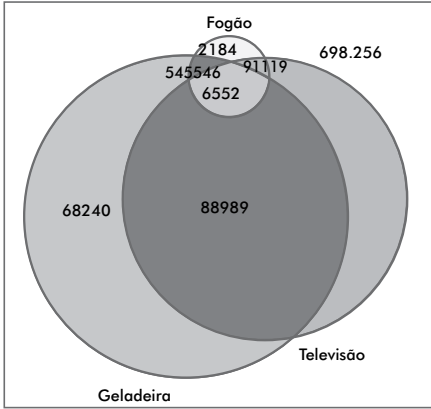

B. Piauí

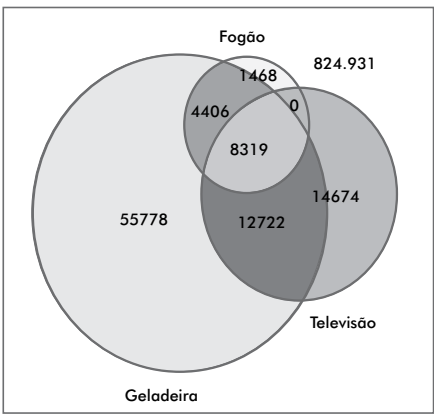

D. lo Grande do Norte

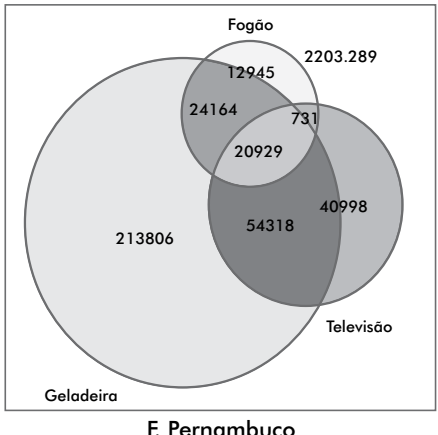

F. Pernambuco

Fonte: Elaboração própria com base em dados da PNAD 2009

fogão, nem televisão e nem geladeira, com $28,83 \%$ e 27,20\%, respectivamente. Ou seja, apenas dois estados da região são responsáveis por mais da metade dos domicílios nordestinos que não possuem nenhum dos três itens de consumo. Na sequência, o estado de Pernambuco participa com 13,21\% e o Ceará tem uma participação de 12,39\%.

Como pode ser visto no Anexo 2, os estados do Maranhão e Piauí, mais uma vez, são os que apresentam maiores necessidades no que diz respeito à falta de televisão 
Figura 5b - Total de famílias com carência de alguns itens de consumo, Nordeste e Estados do Nordeste, 2009

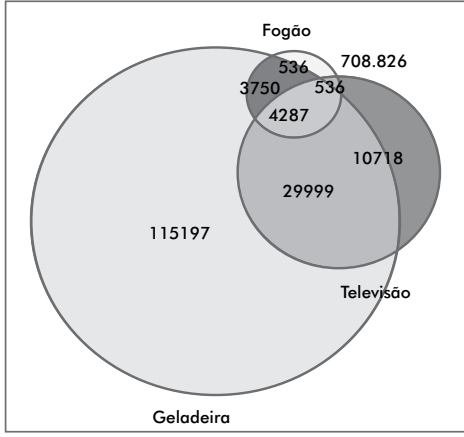

G. Alagoas

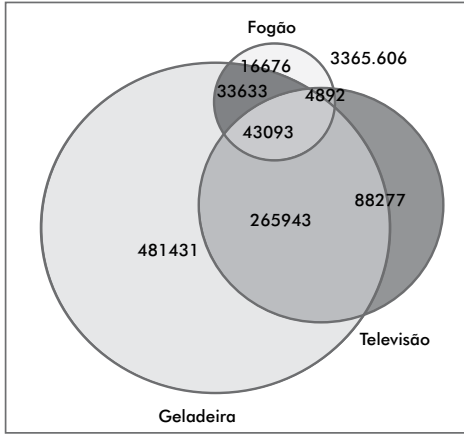

I. Bahia

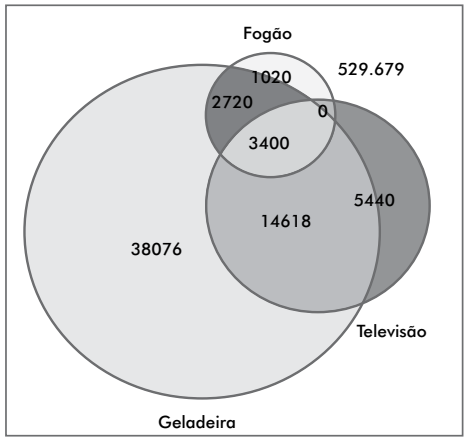

H. Sergipe

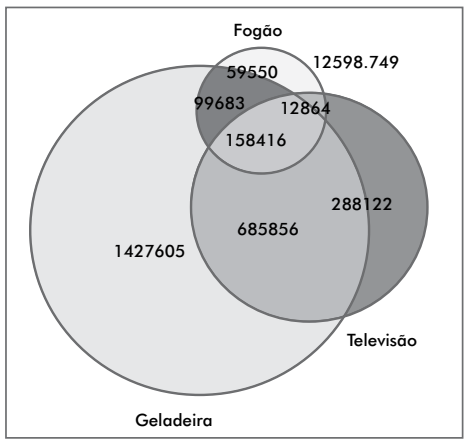

J. Nordeste

Fonte: Elaboração própria com base em dados da PNAD 2009

(12,69\% e 14,19\%, respectivamente). Enquanto isso, um resultado ainda menos satisfatório é observado sobre o percentual de famílias nordestinas que não possuem acesso à geladeira, sendo a Bahia o estado com pior resultado (19,17\%) e o Rio Grande do Norte no extremo oposto, com o menor valor percentual $(8,81 \%)$.

\section{RENDA COMO MEDIDA DE POBREZA}

Para se ter uma dimensão da pobreza em termos de renda domiciliar per capita contrastada com as demais variáveis utilizadas neste estudo, foram elaboradas sobreposições incluindo variáveis de renda e as variáveis de habitação e consumo que foram utilizadas na seção anterior. Para tanto, foi criada uma variável binária de renda, em que aqueles domicílios com renda domiciliar per capita superior à linha de pobreza 
assumem valor igual a 1, e aqueles que se encontram abaixo da linha de pobreza tem valor igual a zero.

Foi estabelecida a linha de pobreza e indigência igual à utilizada pelo Instituto de Pesquisa Econômica Aplicada (IPEA) para o ano de 2009 a valores correntes. Como o IPEA não segmenta as linhas de pobreza de forma tão detalhada quanto a análise no presente trabalho (estadual), foram utilizadas aqui apenas as linhas de pobreza e indigência para as áreas urbanas e rurais da região Nordeste.

A área urbana do Nordeste possui uma linha de pobreza de $\mathrm{R} \$ 201,03$, enquanto as áreas rurais, em média, têm uma linha de pobreza de $\mathrm{R} \$ 179,29$. Com relação à linha de indigência, o IPEA optou por utilizar a metade da linha de pobreza, sendo, portanto, de $\mathrm{R} \$ 100,51$ para as áreas urbanas e $\mathrm{R} \$ 89,65$ para as áreas rurais desta região.

Figura 6 - Domicílios pobres/indigentes, TIPO 3, Nordeste Urbano e Rural, 2009

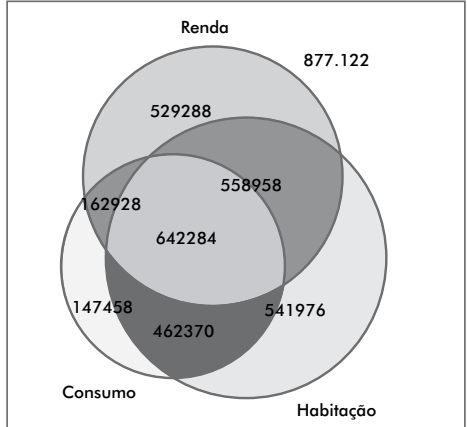

Pobres Nordeste Rural

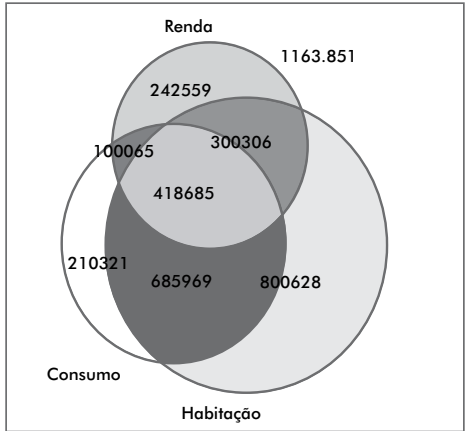

Indigentes Nordeste Rural

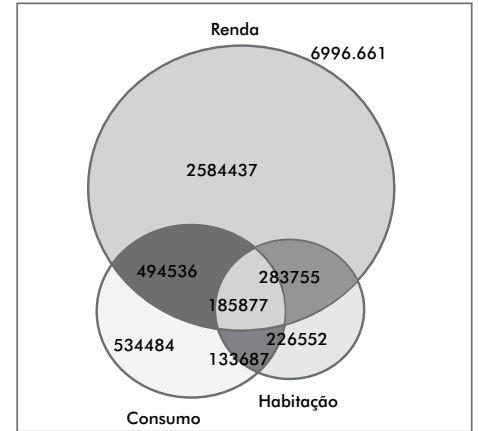

Pobres Nordeste Urbano

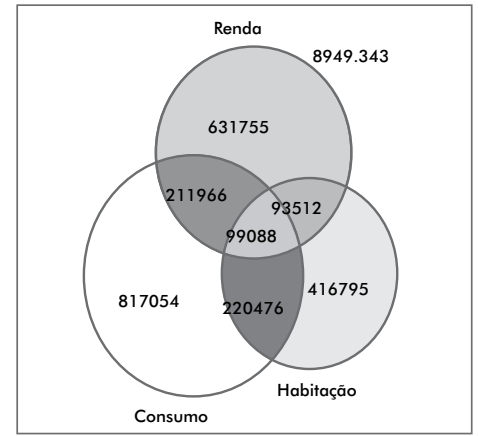

Indigentes Nordeste Urbano

Fonte: Elaboração própria com base em dados da PNAD 2009.

A Figura 6 apresenta os resultados para os domicílios do TIPO 3, cuja carência se dá em pelo menos um item de habitação, pelo menos um item de consumo e renda 
abaixo da linha de pobreza/indigência, tanto para as áreas urbanas quanto rurais do Nordeste.

Uma importante característica que se deve destacar é que, nos quatro diagramas, embora o número total de domicílios nas áreas urbanas seja maior do que na área rural, o tamanho da interseção das três dimensões é maior nas áreas rurais. Ou seja, tanto em termos absolutos quanto percentuais, as áreas rurais do Nordeste apresentam maior número de pessoas pobres e indigentes comparativamente às áreas urbanas.

Tabela 1 - Domicílios nordestinos com privações de componentes relacionados à habitação, consumo e renda, 2009

\begin{tabular}{|c|c|c|c|c|c|c|c|c|c|}
\hline & & \multicolumn{8}{|c|}{ Valores Absolutos } \\
\hline & & $\begin{array}{c}\text { Total } \\
\text { Domicílios }\end{array}$ & $\begin{array}{l}\text { Renda } \\
\text { (R) }\end{array}$ & $\begin{array}{l}\text { Habitação } \\
\text { (H) }\end{array}$ & $\begin{array}{c}\text { Consumo } \\
\text { (C) }\end{array}$ & RH & $\mathrm{HC}$ & RC & RHC \\
\hline \multirow{4}{*}{ Tipo 1} & Pobre Rural & 3.922 .384 & 1.893 .458 & 231.045 & 97.051 & 131.368 & 39.598 & 54.045 & 25.017 \\
\hline & Pobre Urbano & 11.439 .989 & 3.548 .605 & 15.339 & 61.365 & 11.453 & 4.424 & 21.391 & 2.309 \\
\hline & Indigente Rural & 3.922 .384 & 1.061 .615 & 231.045 & 97.051 & 90.060 & 39.598 & 40.959 & 19.871 \\
\hline & Indigente Urbano & 11.439 .989 & 1.036 .321 & 15.339 & 61.365 & 6.368 & 4.424 & 12.306 & 1.279 \\
\hline \multirow{4}{*}{ Tipo 2} & Pobre Rural & 3.922 .384 & 1.893 .458 & 1.054 .221 & 657.543 & 603.980 & 456.258 & 352.247 & 255.115 \\
\hline & Pobre Urbano & 11.439 .989 & 3.548 .605 & 168.084 & 330.804 & 102.957 & 46.634 & 141.125 & 24.699 \\
\hline & Indigente Rural & 3.922 .384 & 1.061 .615 & 1.054 .221 & 657.543 & 388.025 & 456.258 & 236.749 & 174.704 \\
\hline & Indigente Urbano & 11.439 .989 & 1.036 .321 & 168.084 & 330.804 & 46.890 & 46.634 & 68.893 & 11.599 \\
\hline \multirow{6}{*}{ Tipo 3} & Pobre Rural & 3.922 .384 & 1.893 .458 & 2.205 .588 & 1.415 .040 & 1.201 .242 & 1.104 .654 & 805.212 & 642.284 \\
\hline & Pobre Urbano & 11.439 .989 & 3.548 .605 & 829.871 & 1.348 .584 & 469.632 & 319.564 & 680.413 & 185.877 \\
\hline & Indigente Rural & 3.922 .384 & 1.061 .615 & 2.205 .588 & 1.415 .040 & 718.991 & 1.104 .654 & 518.750 & 418.685 \\
\hline & Indigente Urbano & 11.439 .989 & 1.036 .321 & 829.871 & 1.348 .584 & 192.600 & 319.564 & 311.054 & 99.088 \\
\hline & \multicolumn{9}{|c|}{ Percentual com relação ao total de domicílios (\%) } \\
\hline & & & Renda (R) & $\begin{array}{c}\text { Habitação } \\
(\mathrm{H})\end{array}$ & $\begin{array}{c}\text { Consumo } \\
\text { (C) }\end{array}$ & RH & $\mathrm{HC}$ & RC & RHC \\
\hline \multirow{4}{*}{ Tipo 1} & Pobre Rural & & 48,27 & 5,89 & 2,47 & 3,35 & 1,01 & 1,38 & 0,64 \\
\hline & Pobre Urbano & & 31,02 & 0,13 & 0,54 & 0,10 & 0,04 & 0,19 & 0,02 \\
\hline & Indigente Rural & & 27,07 & 5,89 & 2,47 & 2,30 & 1,01 & 1,04 & 0,51 \\
\hline & Indigente Urbano & & 9,06 & 0,13 & 0,54 & 0,06 & 0,04 & 0,11 & 0,01 \\
\hline \multirow{4}{*}{ Tipo 2} & Pobre Rural & & 48,27 & 26,88 & 16,76 & 15,40 & 11,63 & 8,98 & 6,50 \\
\hline & Pobre Urbano & & 31,02 & 1,47 & 2,89 & 0,90 & 0,41 & 1,23 & 0,22 \\
\hline & Indigente Rural & & 27,07 & 26,88 & 16,76 & 9,89 & 11,63 & 6,04 & 4,45 \\
\hline & Indigente Urbano & & 9,06 & 1,47 & 2,89 & 0,41 & 0,41 & 0,60 & 0,10 \\
\hline \multirow{4}{*}{ Tipo 3} & Pobre Rural & & 48,27 & 56,23 & 36,08 & 30,63 & 28,16 & 20,53 & 16,37 \\
\hline & Pobre Urbano & & 31,02 & 7,25 & 11,79 & 4,11 & 2,79 & 5,95 & 1,62 \\
\hline & Indigente Rural & & 27,07 & 56,23 & 36,08 & 18,33 & 28,16 & 13,23 & 10,67 \\
\hline & Indigente Urbano & & 9,06 & 7,25 & 11,79 & 1,68 & 2,79 & 2,72 & 0,87 \\
\hline
\end{tabular}

Fonte: Elaboração própria com base em dados da PNAD 2009.

Como pode ser visto na Tabela 1, 642.284 domicílios da zona rural nordestina estão na interseção das três circunferências, podendo ser considerados pobres do TIPO 3, enquanto 185.877 domicílios da zona urbana estão na mesma condição. Ou seja, na zona rural existem quase 3,5 vezes mais domicílios pobres do que na zona urbana. 
Com relação aos valores percentuais, verificou-se que quase metade da população rural nordestina é pobre $(48,27 \%)$, de acordo com a linha de pobreza estabelecida pelo IPEA, enquanto $31,02 \%$ na zona urbana estão na mesma situação. No que se refere aos indigentes, $27,07 \%$ dos domicílios na zona rural nordestina se enquadram como tal, enquanto apenas pouco mais de $9 \%$ estão na mesma situação nas zonas urbanas desta região, o que, em termos absolutos, equivale a valores semelhantes: $1.061 .615 \mathrm{e}$ 1.036.321 domicílios nas áreas rurais e urbanas, respectivamente.

Como dito anteriormente, foram escolhidos para uma análise mais detalhada os domicílios pobres do TIPO 3. No entanto, a Tabela 1 nos oferece dados importantes para analisar o grave problema enfrentado pela população rural nordestina que vive em domicílios classificados como TIPO 1 e TIPO 2. Dos domicílios pobres do TIPO 2 do Nordeste rural, 6,50\% encontram-se na interseção das dimensões, ou seja, estão abaixo da linha de pobreza, não possuem dois (ou nenhum dos três) bens de consumo e nem dois (ou nenhum dos três) serviços de habitação, enquanto 4,45\% estão abaixo da linha de indigência de renda, além de características semelhantes para consumo e habitação. Os resultados para as áreas urbanas são pouco significantes, representados por $0,22 \%$ de pobres e $0,10 \%$ de indigentes. Já com relação ao TIPO 3, 16,37\% dos domicílios são considerados pobres, enquanto $10,67 \%$ são considerados indigentes nas três dimensões.

A Tabela 2 mostra a análise para os pobres do TIPO 4 e do TIPO 5. Os domicílios enquadrados nos pobres do TIPO 4 são aqueles que não são carentes de renda, mas que são carentes de pelo menos um item de habitação e um de consumo. Ou seja, possuem renda acima do nível de pobreza/indigência estabelecido pelo IPEA e ainda assim necessitam de pelo menos uma das variáveis analisadas de habitação e consumo. Esta análise é importante por mostrar a deficiência da análise da pobreza medida exclusivamente a partir da renda. Isso porque nos domicílios pode ser que não haja os bens de consumo/habitação por vontade de seus moradores, que teriam condições financeiras para ter acesso a eles, ou porque a renda estabelecida como piso para manter as necessidades mínimas não é suficiente para atender a esses requisitos, ou, ainda, há a possibilidade de os moradores dos domicílios terem condições financeiras e desejo de consumir esses bens, mas a cidade onde estão localizados não oferecer a infraestrutura necessária para que isso se torne possível, como sistema de esgoto ou oferta de energia.

Observa-se, na Tabela 2, que dos 11.439.989 domicílios da área urbana da região Nordeste, $61,16 \%$ possuem renda acima da linha de pobreza, e 76,75\% possuem renda acima da linha de indigência (incluindo aqueles domicílios considerados pobres e os não pobres). Os dados para as áreas rurais são muito mais preocupantes, pois apenas 22,36\% dos domicílios estão acima da linha de pobreza, enquanto 30,75\% estão acima da linha de indigência (de um total de 3.922.384 domicílios). 
Quando a análise é feita para carência dos itens das dimensões de consumo e habitação, percebe-se que a proporção nas áreas rurais é muito maior do que nas áreas urbanas. Ou seja, nas áreas rurais, menos domicílios têm renda acima da linha de pobreza/indigência e mais domicílios são carentes nas demais dimensões, o que nos leva a inferir que a situação dos domicílios destas áreas é muito mais grave do que nas áreas urbanas e, por isso, dentre outras razões, merece prioridade na elaboração de políticas de desenvolvimento.

Tabela 2 - Total de Domicílios Pobres/Indigentes, TIPO 4 e TIPO 5, Nordeste Urbano e Nordeste Rural, 2009(*)

\begin{tabular}{|c|c|c|c|c|c|c|c|c|c|}
\hline & & \multicolumn{8}{|c|}{ Pobre do TIPO 4} \\
\hline & & $\begin{array}{c}\text { Total de } \\
\text { domicílios no } \\
\text { Nordeste }\end{array}$ & $\begin{array}{l}\text { Não é pobre } \\
\text { por Renda } \\
\left(\mathbf{R}^{\prime}\right)\end{array}$ & $\begin{array}{c}\text { Carente em } \\
\text { Habitação } \\
\text { (H) }\end{array}$ & $\begin{array}{l}\text { Carente em } \\
\text { Consumo } \\
\text { (C) }\end{array}$ & R'H & $\mathrm{HC}$ & R'C & R'HC \\
\hline \multirow{4}{*}{$\begin{array}{l}\text { Valores } \\
\text { Absolutos }\end{array}$} & Pobre Urb. & 11.439 .989 & 6.996 .661 & 283.755 & 494.536 & 226.552 & 185.877 & 534.484 & 133.687 \\
\hline & Indigente Urb. & 11.439 .989 & 8.780 .091 & 119.245 & 259.115 & 391.062 & 115.277 & 769.905 & 204.287 \\
\hline & Pobre Rur. & 3.922 .384 & 877.122 & 558.958 & 162.928 & 541.976 & 642.284 & 147.458 & 462.370 \\
\hline & Indigente Rur. & 3.922 .384 & 1.206 .021 & 249.384 & 87.172 & 851.550 & 360.367 & 223.214 & 744.287 \\
\hline \multirow{6}{*}{ Valores \% } & Pobre Urb. & - & $61,16 \%$ & $2,48 \%$ & $4,32 \%$ & $1,98 \%$ & $1,62 \%$ & $4,67 \%$ & $1,17 \%$ \\
\hline & Indigente Urb. & - & $76,75 \%$ & $1,04 \%$ & $2,26 \%$ & $3,42 \%$ & $1,01 \%$ & $6,73 \%$ & $1,79 \%$ \\
\hline & Pobre Rur. & - & $22,36 \%$ & $14,25 \%$ & $4,15 \%$ & $13,82 \%$ & $16,37 \%$ & $3,76 \%$ & $11,79 \%$ \\
\hline & Indigente Rur. & - & $30,75 \%$ & $6,36 \%$ & $2,22 \%$ & $21,71 \%$ & $9,19 \%$ & $5,69 \%$ & $18,98 \%$ \\
\hline & & \multicolumn{8}{|c|}{ Pobre do TIPO 5} \\
\hline & & $\begin{array}{c}\text { Total de } \\
\text { domicílios no } \\
\text { Nordeste }\end{array}$ & $\begin{array}{c}\text { É pobre por } \\
\text { Renda (R) }\end{array}$ & $\begin{array}{c}\text { Não é } \\
\text { carente em } \\
\text { Habitação } \\
\left(H^{\prime}\right)\end{array}$ & $\begin{array}{c}\text { Não é carente } \\
\text { em Consumo } \\
\left(C^{\prime}\right)\end{array}$ & $\mathbf{R H}^{\prime}$ & $\mathrm{H}^{\prime} \mathrm{C}^{\prime}$ & RC' & RH'C' \\
\hline \multirow{4}{*}{$\begin{array}{l}\text { Valores } \\
\text { Absolutos }\end{array}$} & Pobre Urb. & 11.439 .989 & 194.418 & 513.304 & 226.552 & 485.995 & 6.996 .661 & 283.755 & 2.584 .437 \\
\hline & Indigente Urb. & 11.439 .989 & 119.607 & 744.514 & 391.062 & 254.785 & 8.780 .091 & 119.245 & 801.007 \\
\hline & Pobre Rur. & 3.922 .384 & 642.528 & 145.895 & 541.976 & 162.684 & 877.122 & 558.958 & 529.288 \\
\hline & Indigente Rur. & 3.922 .384 & 360.367 & 221.407 & 851.550 & 87.172 & 1.206 .021 & 249.384 & 200.389 \\
\hline \multirow{4}{*}{ Valores \% } & Pobre Urb. & - & $1,70 \%$ & $4,49 \%$ & $1,98 \%$ & $4,25 \%$ & $61,16 \%$ & $2,48 \%$ & $22,59 \%$ \\
\hline & Indigente Urb. & - & $1,05 \%$ & $6,51 \%$ & $3,42 \%$ & $2,23 \%$ & $76,75 \%$ & $1,04 \%$ & $7,00 \%$ \\
\hline & Pobre Rur. & - & $16,38 \%$ & $3,72 \%$ & $13,82 \%$ & $4,15 \%$ & $22,36 \%$ & $14,25 \%$ & $13,49 \%$ \\
\hline & Indigente Rur. & - & $9,19 \%$ & $5,64 \%$ & $21,71 \%$ & $2,22 \%$ & $30,75 \%$ & $6,36 \%$ & $5,11 \%$ \\
\hline
\end{tabular}

Nota: ${ }^{*}$ ) Os valores representados nesta tabela referem-se aos totais em cada uma das dimensões, já subtraídos da interseção entre as três variáveis.

Fonte: Elaboração própria com base emdados da PNAD 2009

Na região urbana do Nordeste, existem 133.687 domicílios classificados como TIPO 4 que estão na interseção das três dimensões quando a linha considerada é a de pobreza, enquanto 204.287 estão na interseção quando considerada a linha de indigência. Isso representa apenas $1,17 \%$ e $1,79 \%$, respectivamente, do total de domicílios das áreas urbanas da região.

Quando voltamos a análise para as áreas rurais, verifica-se que 462.370 domicílios estão na interseção das três dimensões quando a linha considerada é a de pobreza, 
enquanto 744.287 estão na interseção quando considerada a linha de indigência, o que representa $11,79 \%$ e $18,98 \%$ do total de domicílios das áreas rurais do Nordeste.

Ou seja, em termos absolutos, o número de domicílios rurais incluído na interseção das três dimensões é, em média, 3,5 vezes mais do que o número de domicílios das áreas urbanas compreendidos na interseção das três variáveis, tanto no que se refereaos níveis de pobreza quanto aos de indigência.

Com relação aos domicílios do TIPO 5, também apresentados na Tabela 2, foram considerados aqueles que são carentes de renda (ou seja, estão abaixo dos níveis de pobreza/indigência), mas que possuem os três itens de cada uma das outras dimensões. Ou seja, possuem geladeira, fogão, televisão, saneamento, água canalizada e energia elétrica.

Do total de domicílios da área urbana, 194.418 estão abaixo da linha de pobreza (apenas 1,70\%) e 119.607 estão abaixo da linha de indigência (1,05\%). Já nas áreas rurais, a situação é muito mais grave. O número de domicílios pobres e indigentes das áreas rurais é mais de três vezes o número de domicílios pobres e indigentes das áreas urbanas. São considerados pobres 642.528 domicílios na zona rural (o equivalente a $16,38 \%$ do total de domicílios dessa mesma região), enquanto 360.367 estão abaixo da linha de extrema pobreza, o que equivale a $9,19 \%$ do total de domicílios dessa região. A quantidade de domicílios pobres por renda nas áreas rurais é mais de três vezes o número de domicílios pobres das áreas urbanas, pelo mesmo critério.

Na região urbana do Nordeste, 2.584 .437 domicílios estão na interseção das três dimensões quando analisada a classificação do TIPO 5 (não são carentes em nenhum dos três itens consumo e habitação, mas estão abaixo da linha de pobreza/indigência) e quando a linha considerada é a de pobreza, ao passo que 801.007 estão da interseção quando considerada a linha de indigência. Isso representa $22,59 \%$ e $7,00 \%$, respectivamente, do total de domicílios pobres e indigentes das áreas urbanas da região Nordeste. Quando voltamos à análise dos domicílios do TIPO 5 das áreas rurais, verificamos que 529.288 estão na interseção das três dimensões quando a linha considerada é a de pobreza, enquanto 200.389 estão na interseção quando considerada a linha de indigência, o que representa $13,49 \%$ e 5,11\% do total de domicílios das áreas rurais do Nordeste. Ou seja, em termos absolutos, o número de domicílios urbanos incluídos da interseção das três dimensões é quase cinco vezes maior do que o número de domicílios das áreas rurais compreendidos na interseção das três variáveis quando nos referimos ao nível de pobreza, e quase quatro vezes mais quando nos referimos aos níveis de extrema pobreza (indigência).

Com esses dados, pode-se ter uma ideia da magnitude da pobreza nordestina e o quão intensa e perversa ela é nessa região. Espera-se que este trabalho possa servir como base para elaborações de políticas públicas voltadas para estas áreas, de modo que se consiga minimizar os efeitos adversos intrínsecos a este problema. 


\section{CONCLUSÕES}

Com o objetivo de auxiliar nas futuras políticas públicas de combate à pobreza e à pobreza extrema no país, que é um dos mais graves problemas enfrentados pela população brasileira, especialmente a nordestina, esta pesquisa pretende ampliar e detalhar a análise sobre o perfil da pobreza no Nordeste do Brasil, utilizando-se, para isso, as variáveis de habitação e consumo que, possivelmente, possuem um papel importante na caracterização deste entrave econômico-social.

Os cálculos foram feitos a partir dos dados da PNAD do IBGE para o ano de 2009. Deve ser lembrado que a base de dados utilizada capta apenas os rendimentos em dinheiro, não levando em consideração o valor da produção para autoconsumo, que representa uma importante parcela da renda real dos pequenos agricultores, que estão basicamente concentrados nas áreas rurais. Este é um dos motivos pelos quais o critério apenas da renda para avaliação da pobreza não está bem fundamentado.

Foram estimadas sobreposições entre três variáveis de habitação (acesso à energia elétrica, saneamento e água canalizada) e consumo de bens duráveis (geladeira, televisão e fogão), de modo que se pudesse observar tanto em termos percentuais quanto absolutos aqueles domicílios que não possuem acesso a esses bens.

Como discutido, verificou-se que o Nordeste apresenta um dos maiores percentuais de domicílios sem acesso aos itens de habitação e consumo e, além disso, ainda é o pior em termos absolutos, apesar de o Sudeste ser a região mais populosa. Na dimensão de habitação, o item mais escasso é a água canalizada, seguido pelo esgotamento sanitário e energia elétrica, enquanto na dimensão de consumo o item geladeira é o que mais falta nos domicílios brasileiros.

Dos domicílios pobres do TIPO 2 do Nordeste, 6,50\% encontram-se na interseção das três dimensões, ou seja, estão abaixo da linha de pobreza, não possuem pelo menos dois bens de consumo e nem dois (ou nenhum dos três) serviços de habitação, enquanto 4,45\% estão abaixo da linha de indigência de renda, além de características semelhantes para consumo e habitação. Com relação ao TIPO 3, 16,37\% dos domicílios são considerados pobres, enquanto $10,67 \%$ são considerados indigentes nas três dimensões.

A análise feita para os pobres do TIPO 4 mostra que apenas 1,17\% e 1,79\% do total de domicílios das áreas urbanas da região Nordeste estão na interseção das três dimensões quando a linha considerada é a de pobreza, enquanto 11,79\% e 18,98\% do total de domicílios das áreas rurais do Nordeste estão na interseção das três variáveis quando considerada a linha de indigência. Isso significa que, em média, o número de domicílios rurais incluído da interseção das três dimensões é 3,5 vezes maior do que o número de domicílios das áreas urbanas compreendidos na interseção das três variáveis, tanto referente aos níveis de pobreza quanto aos de indigência. 
No que se refere àqueles domicílios classificados como TIPO 5, 22,59\% dos domicílios da região urbana do Nordeste estão na interseção das três dimensões quando considerada a linha de pobreza, enquanto 7,00\% estão da interseção das três dimensões considerando-se a linha de indigência.Com relação à área rural da região, 13,49\% dos domicílios estão na interseção das três dimensões quando a linha considerada é a de pobreza, enquanto $5,11 \%$ estão na interseção quando considerada a linha de indigência.

Espera-se, com essa pesquisa, compreender como determinadas variáveis estão presentes na caracterização da pobreza nordestina e, com isso, auxiliar no direcionamento de políticas públicas mais eficientes, de modo que se consiga reduzir os efeitos adversos deste mal, principalmente entre a população rural da região.

\section{REFERÊNCIAS BIBLIOGRÁFICAS}

ALKIRE, S.; SANTOS, M. E. Acute multidimensional poverty: a new index for developing countries. OPHI Working Paper, University of Oxford, n. 38, 2010.

ALKIRE, S.; FOSTER, J. Counting and multidimensional poverty measurement. Journal of Public Economics, v. 95, n. 7-8, p. 476-487, 2011.

ANAND, S.; SEN, A. Concepts of human development and poverty: a multidimensional perspective. United Nations Development Programme, Poverty and human development: Human development papers. New York: United Nations, p. 1-20, 1997.

ARBACHE, J. S. Pobreza e mercados no Brasil - uma análise de iniciativas de políticas públicas. Santiago do Chile: CEPAL, 2003.

BOURGUIGNON, F.; CHAKRAVARTY, S. R. The measurement of multidimensional poverty. Journal of Economic Inequality, n. 1, p. 25-49, 2003.

MARIANO, J. L.; NEDER, H. D. Renda e pobreza entre famílias no meio rural do Nordeste. In: Encontro Nacional de Economia Política, 9, Uberlândia, MG. Anais... Uberlândia: SEP, 2004.

MARIN, S. R.; OTTONELLI, J. Medida multidimensional da pobreza: um exercício em Palmeira das Missões - RS. REDES, Santa Cruz do Sul, v. 13, n. 3, p. 241-265, set./dez. 2008.

ROCHA, S. Governabilidade e pobreza - o desafio dos números. Texto para Discussão, IPEA, n. 368, 1995. 


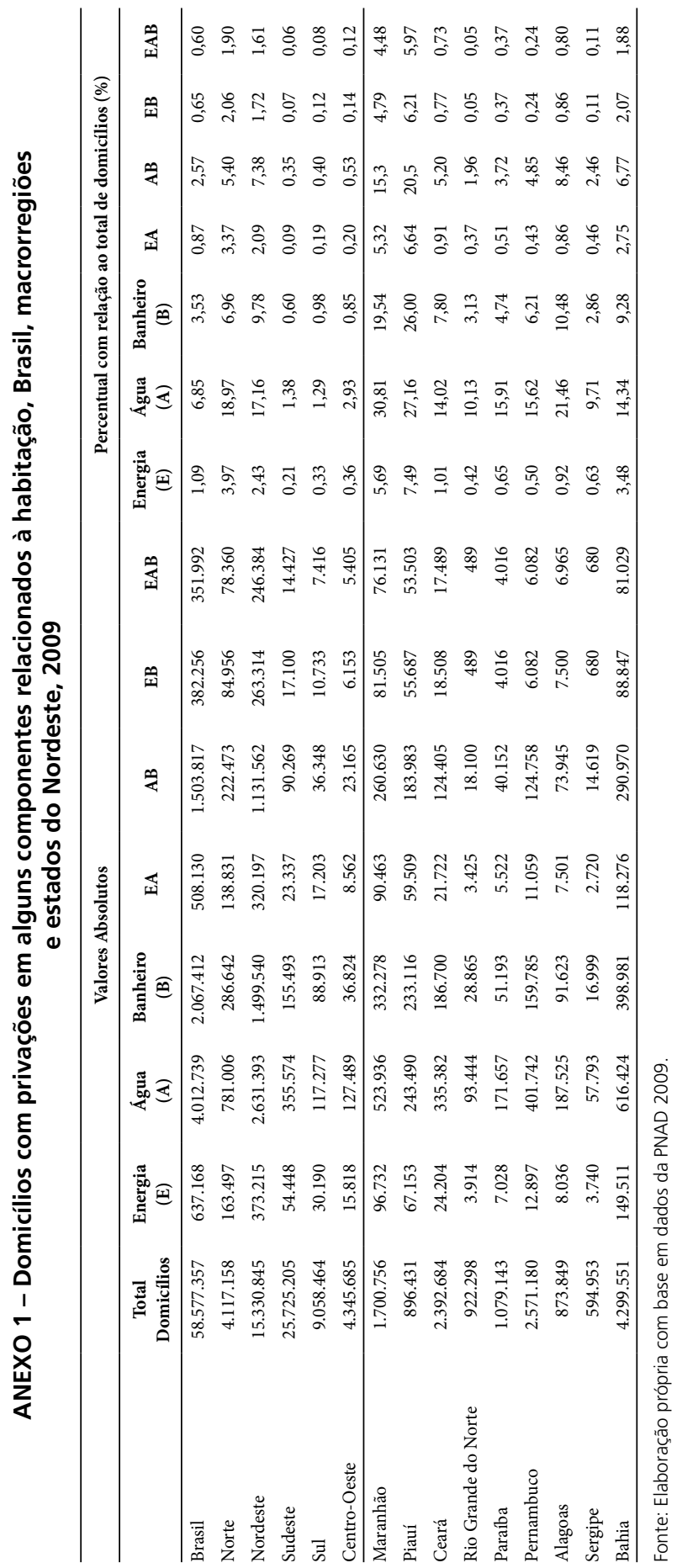




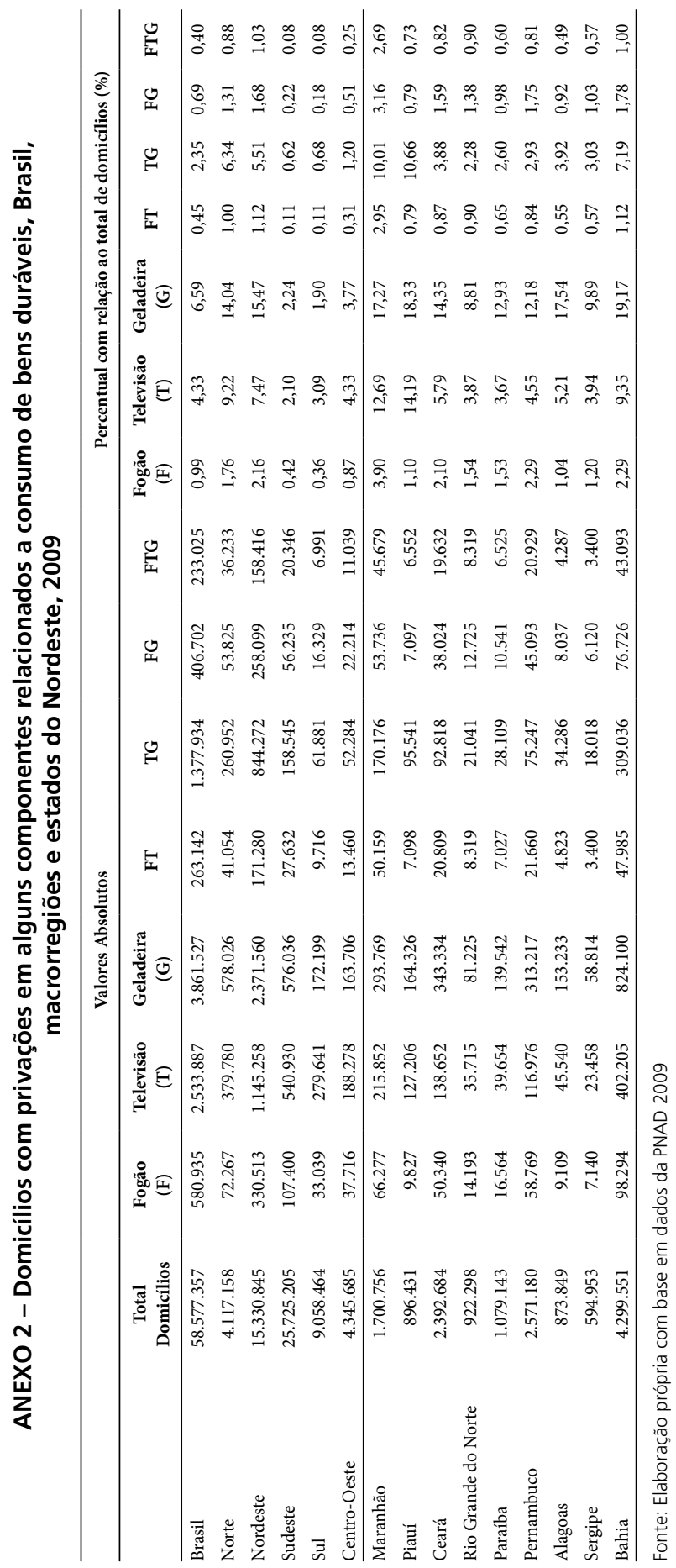

